\title{
Psychological Differences of Patients and Relatives according to Post-Transplantation Anxiety
}

\author{
María Ángeles Pérez San Gregorio ${ }^{1}$ \\ Agustín Martín Rodríguez ${ }^{1}$ \\ José Pérez Bernal ${ }^{2}$ \\ ${ }^{1}$ Universidad de Sevilla \\ ${ }^{2}$ Hospital Universitario Virgen del Rocío de Sevilla
}

\begin{abstract}
The aim of this investigation is to analyze the psychological differences of patients and their relatives according to the formers' post-transplantation anxiety. We used two groups of participants: transplant patients $(n=166)$ and close relatives $(n=166)$. Four questionnaires were applied: a Psychological Survey (to both groups), the Hospital Anxiety and Depression Scale, and the Quality of Life Questionnaire (to the transplant patients), and the Leeds Scales for the Self-Assessment of Anxiety and Depression (to the relatives). Participants were assessed twice: post-Intensive Care Unit (ICU; when patients were moved from the ICU to the Transplantation Unit) and post-hospital (one year after transplant). Results showed that high anxiety in patients just after organ transplant was related to an increase of anxiety and depression symptoms both in patients and relatives one year after transplant; it was also related to a decrease in the quality of life of these patients.
\end{abstract}

Keywords: organ transplant, anxiety, depression, quality of life

\begin{abstract}
El objetivo de esta investigación es analizar las diferencias psicológicas en pacientes y familiares en función de la ansiedad post-trasplante. Seleccionamos dos grupos: 166 trasplantados y los 166 familiares más allegados de estos pacientes. Empleamos una Encuesta Psicosocial (en ambos grupos), la Escala de Ansiedad y Depresión en Hospital y el Cuestionario de Calidad de Vida (en el grupo de trasplantados) y las Escalas de Ansiedad y Depresión de Leeds (en el grupo de familiares). La evaluación psicológica se realizó en dos fases: post-UCl (cuando a los pacientes se les daba el alta de la UCI pero continuaban ingresados en el hospital, concretamente, en la Unidad de Trasplantes) y post-hospitalaria (cuando transcurría un año del alta hospitalaria de los pacientes tras el implante). Los resultados mostraron que un nivel alto de ansiedad en los pacientes tras el trasplante, aumentaba al año la sintomatología ansiosa y depresiva de los pacientes y de sus familiares y, además, empeoraba la calidad de vida de los trasplantados.

Palabras clave: trasplante de órganos, ansiedad, depresión, calidad de vida
\end{abstract}

This investigation was financed by the Plan Nacional de Investigación Científica, Desarrollo e Innovación Tecnológica (I+D+I) and the Instituto de Salud Carlos III (Subdirección General de Evaluación y Fomento de la Investigación) (File n PI060095).

Correspondence concerning this article should be addressed to $\mathrm{M}^{\mathrm{a}}$ Ángeles Pérez San Gregorio, Facultad de Psicología, Departamento de Personalidad, Evaluación y Tratamiento Psicológicos, Universidad de Sevilla, C/. Camilo José Cela, s/n, 41018-Sevilla (Spain). Phone: 954-556-939. Fax: 954-557-807. E-mail: anperez@us.es

Translation: Virginia Navascués Howard. 
Organ transplant is a therapeutic alternative that offers patients more quantity and quality of life. However, it must be taken into account that not all patients attain better physical, psychological, and social well-being. For example, in an investigation carried out with liver transplant patients, it was found that $60 \%$ of the patients considered that their life had not become normalized after transplantation, mainly due to the presence of diverse physical and psychological problems: secondary effects of medication, fatigue, gastrointestinal problems, osteoporosis, and depression (Holzner et al., 2001). Along these lines, in a review by Pérez, Martín, and Galán (2005), the authors concluded that transplant patients could suffer from various psychological complications, such as: immediate post-operation delirium caused by immunosupressor medication, sexual disorders caused either by physical (the disease itself or the medication) or psychological factors (fear of harming the transplanted organ), mood disorders that decrease postoperation adherence to treatment and that can cause organ rejection, anxiety disorders, especially when patients are discharged, fantasies about the donor that can lead to feelings of guilt because they think the donor died so they could live, and dissatisfaction with body image, because they perceive the organ as a foreign object that transfers the donor's traits to them. Other studies have attempted to identify the most stressful situations for patients, which can have negative consequences on their evolution: for example, uncertainty about their future health, secondary effects of medication, limitations associated with their physical status, and medical prescriptions (Achille et al., 2004; Dew, Myaskovsky, Switzer, DiMartini, \& Kormos, 2005).

However, it must be remembered that the transplantation process also affects the relatives, both in the stage immediately after transplantation-for example, adaptation to the therapeutic prescriptions and recovery from surgeryand long-term-for example, the possibility of patients' chronic organ rejection and fear of their dying (Collins, White, \& Jalowiec, 2000). All of this affects the caregivers' mental health, so that various anxiety and depressive disorders may appear in them (Dew et al., 2004).

Among the factors that determine the psychological wellbeing of transplant patients and their relatives, the studies have focused on the influence of social support (Frazier, Tix, Klein, \& Arikian, 2000; Wang, Chang, Shih, Sun, \& Jeng, 2006), hospitalization (Dew, DiMartini, et al., 2000; Pérez, Martín, Asián, \& Pérez, 2004), pre- and posttransplantation expectations (Pérez, Martín, Gallego, \& Santamaría, 2000), coping strategies (Christensen, Raichle, Ehlers, \& Bertolatus, 2002), the duration of the disease (Owen, Bonds, \& Wellisch, 2006; Trumper \& Appleby, 2001), the etiology of the transplantation (Gledhill et al., 1999), and the source of the transplanted organ (Watanabe \& Higara, 1999). However, there has been little research that has analyzed the psychological differences in the patients and their relatives as a function of the post-transplantation anxiety experienced by the patients themselves. This kind of studies is necessary, among other reasons, to determine the efficacy of the medical intervention, improve clinical decisions, control patients' evolution in their physical, functional, psychological, and social aspects, understand the quality of life of the patients and their main caregivers, and to program psychosocial interventions and rehabilitation (Moreno \& Kern, 2005; Myaskovsky et al., 2005; Ortega $\&$ Rebollo, 2004). Hence, the purpose of this study is to analyze the psychological differences in patients (anxiety, depression, and quality of life) and their relatives (anxiety and depression) as a function of the level of anxiety (high or low) experienced by the patients shortly after the transplant surgery carried out one year ago.

\section{Method}

\section{Participants}

Two groups that had no psychological and/or psychiatric antecedents were selected: 166 patients who were on the waiting list to receive the first transplant of liver, kidney, or heart, from a deceased donor in the Hospital Universitario Virgen del Rocío de Sevilla [University Hospital of the Virgen del Rocío of Seville] and 166 close relatives of these patients (only one relative for each transplant patient).

The transplant group was made up of $69.27 \%$ males and $30.73 \%$ females, mean age 48.91 years $(S D=11.22$ years, range $=20-68)$. With regard to the type of transplanted organ, there was a predominance of liver transplantations (47\%), followed by kidneys (42.8\%), and hearts $(10.2 \%)$. Mean stay in hospital was 8.06 days in the Intensive Care Unit (ICU) for Transplantations and 17.88 days in the Transplantation Unit of the hospital. The 166 transplanted organs proceeded from people who had died due to the following causes: cerebrovascular accidents (53.7\%), traumatic brain injury $(40.2 \%)$, and others $(6.1 \%)$.

The group of relatives was made up of $25 \%$ males and $75 \%$ females, mean age 43.65 years $(S D=13.18$ years, range $=18-76)$. Their kinship with the patients was: spouse $(56.8 \%)$, son/daughter $(21.9 \%)$, sibling $(11 \%)$, parent $(8.9 \%)$, and other $(1.4 \%)$. There was a predominance of relatives who lived with the patients $(81.4 \%)$, and, in most cases, their relationship was good $(95.2 \%)$.

\section{Instruments}

Psychosocial Survey: This was elaborated by the authors and adapted to the characteristics of the two groups (patients and relatives) used in this study. It collects sociodemographic data (sex, age, sociocultural and economic level, etc.), medical data (etiology of the transplantation, rejection episodes, etc.), psychological data (expectations towards the disease, experience of highly 
stressful life events, etc.), and family data (whether or not the patient and the relative lived together, the kind of relationship they had, etc.).

The Hospital Anxiety and Depression Scale (HAD; Zigmond \& Snaith, 1983). The traditional measures of affective alterations contain items that can reflect both symptoms of a disease and anxious and depressive manifestations. This led Zigmond and Snaith to develop the HAD, whose content excludes somatic symptoms of anxiety and depression (insomnia, fatigue, loss of appetite, etc.), thus precluding erroneous attribution when applied to patients who suffer from physical diseases. It has 14 items, 7 referring to depression and 7 to anxiety, inquiring about the way the person has felt for the last week. Respondents choose one response from four response possibilities. The test provides two scores, one for Anxiety and one for Depression. In both cases, scores are classified as: normal (0-7 points), doubtful (8-10 points), and clinical cases ( $\geq$ 11 points). This questionnaire has been widely used in the Spanish population, and has been adapted by various authors. We used the version by Caro and Ibáñez (1992). The study of Tejero, Guimera, Farré, and Peri (1986), with psychiatric patients in Spain, obtained an alpha coefficient of .81 for the subscale of Anxiety and of .82 for Depression. The correlation of the Anxiety subscale with the State scale of the State-Trait Anxiety Inventory (STAI; Spielberger, Gorsuch, \& Lushene, 1970) was .71 and the correlation of the Depression subscale with the Beck Depression Inventory (BDI; Beck, Rush, Shaw, \& Emery, 1979) was .74. The main limitation is that both subscales are somewhat correlated $(r=.59)$ and, therefore, they are not completely independent.

The Quality of Life Questionnaire (QLQ-C30; European Organization for Research and Treatment of Cancer [EORTC]). This instrument was created by the Group of Quality of Life of the EORTC. The test's psychometric adequacy, along with its extensive use, has led to its application beyond the population for which it was designed. For example, it has been satisfactorily used with people infected with HIV or AIDS (De Boer, Van Dam, \& Sprangers, 1995) and it was used as a foundation to construct a questionnaire for chronically ill people (Rodríguez, Pastor, \& López, 1993). It is made up of 30 items with various response formats: (a) yes/no for the first 7 items; (b) for items 8-28, Likert-type scores range from 1 (not at all) to 4 (very much); and (c) for the last 2 items, Likert scores range between 1 (very poor) and 7 (excellent). The questionnaire has five functional scales: Physical Functioning, Role Functioning, Social Functioning, Emotional Functioning, and Cognitive Functioning. It also has a Global Health scale, three Symptom scales (Fatigue, Pain, and Nausea-vomiting), and some individual items that reflect difficulties caused by the illness or its treatment (dyspnea, insomnia, loss of appetite, constipation, diarrhea, and financial impact). The questionnaire was validated in a Spanish sample by Arrarás, Illarramendi, and Valerdi (1995), and the result of factor analysis was in accordance with the structure of most of the scales. Seven scales presented alpha coefficients between .65 and .85 , and two values below .60. Osoba, Zee, Pater, Warr, and Latreille (1994) reported a global internal consistency of .78 (alpha), and a criterion validity of .85 when correlating the scale with the Eastern Cooperative Oncological Group scale.

The Leeds Anxiety and Depression Scales (Snaith, Bridge, \& Hamilton, 1976). This instrument was created from the 12 original items of the Wakefield Self-Assessment of Depression Inventory (Snaith, Ahmed, Mehta, \& Hamilton, 1971) to which another 10 items were added; 2 of them from the Anxiety Scale of the Symptom Rating Tests (Kellner \& Sheffield, 1973). The final version comprised 22 items with four response alternatives (very often, sometimes, not often, and never) from which respondents selected one. In addition to providing a Total Anxiety-Depression score, the test provides five other scores: Specific Anxiety, Specific Depression, Differential Score, General Anxiety, and General Depression. In the original study of Snaith et al., the psychometric data were established from a sample of psychiatric patients with anxious and depressive pathologies who self-rated themselves on the 22 items of the scale. In order to obtain external reference scores, these patients were also assessed with the Hamilton Anxiety and Depression Scales (Hamilton, 1959, 1967). When considering the sample of items conjointly, an item was assigned either to the Anxiety or the Depression scale if it correlated higher than .52 with the appropriate external observation rating (anxiety or depression) and its contribution to the variance differed by at least .05 from the correlation of the item with the two reference assessments (anxiety and depression). Lastly, in the crossed validation study, the correlation of the General Depression scale with the observers' estimation was .85 ( $p$ $<.01)$, and that of the General Anxiety scale was .83 ( $p<$ $.01)$. This scale has also been used in Spain in investigations with samples of cardiovascular patients (Bueno \& Buceta, 1997; Garces, Velandrino, Conesa, \& Ortega, 2002). Likewise, this scale is being validated by the authors of the present investigation.

\section{Procedure}

Before beginning the assessment of the participants, we provided information about the investigation, we clarified all their doubts, and they provided written informed consent. They were informed that their participation was voluntary and they could leave the study whenever they wanted to without having to offer any explanations, and this would not affect their medical care.

The transplant patients and their relatives were assessed at two different times: 
Post-ICU Phase. At this time, we administered the HAD (Zigmond \& Snaith, 1983) to the patients, who, after undergoing transplantation surgery, were discharged from the ICU but remained hospitalized in the Transplantation Unit. Diverse sociographic and medical data were obtained with the psychosocial survey, administered both to patients and their close relatives. All the participants (patients and relatives) had a week in which to adapt to the conditions and circumstances of hospitalization before undergoing assessment.

Post-Hospital Phase. Exactly one year after they had been discharged, the transplant patients completed the HAD (Zigmond \& Snaith, 1983) again, and the Quality of Life Questionnaire (the version by Arrarás et al., 1995), whereas their relatives completed the Leeds Anxiety and Depression Scales (Snaith et al., 1976).

According to the classification of Montero and León (2005), this study is a simple prospective ex post facto study. The transplant sample was selected from among 255 patients who were admitted to the hospital during a two-year interval to undergo surgery to receive organ transplantation. When selecting the sample, all the patients had undergone surgery and were hospitalized in the Transplantation Unit (liver, kidney, or heart) after having stayed for some time in the ICU.
Four inclusion criteria were taken into account when selecting the patients: (a) 18 years of age or older; (b) sufficient cognitive capacity to complete the questionnaires, that is, they did not present sensory or mental alterations that prevented spatial-temporal orientation or maintaining a congruent conversation; (c) providing written informed consent to participate in the study; and (d) having received a first organ transplantation (liver, kidney, or heart) from a deceased donor. Out of the original group, 166 patients fulfilled these criteria. However, 35 patients dropped out in the post-hospital phase. The main reasons were: (a) 16 patients had died at follow-up, most of them due to an acute rejection of the organ and subsequent multi-organic failure, and (b) 19 patients and/or their relatives did not wish to collaborate in the second phase of this study.

\section{Statistical Analyses}

In order to analyze the psychological differences of the patients and their relatives as a function of the level of posttransplantation anxiety experienced by the patients, we carried out the following steps:

Table 1

Psychological Differences (Anxiety, Depression from the HAD and Quality of Life from the QLQ) in Transplant Patients as a Function of their Post-Transplantation Anxiety One Year Ago

\begin{tabular}{|c|c|c|c|c|c|c|}
\hline \multirow[b]{3}{*}{ Variables measured one year after Transplantation } & \multicolumn{4}{|c|}{ Post-Transplant Anxiety } & \multirow[b]{3}{*}{ Value of Contrast Statistic } & \multirow[b]{3}{*}{$p$} \\
\hline & \multicolumn{2}{|c|}{ Low } & \multicolumn{2}{|c|}{ High } & & \\
\hline & $M$ & $(S D)$ & $M$ & $(S D)$ & & \\
\hline \multicolumn{7}{|l|}{ HAD Scale } \\
\hline Total Anxiety Score & 4.27 & $(4.42)$ & 6.64 & $(3.29)$ & $t(84)=-2.841$ & $.006^{* *}$ \\
\hline Total Depression Score & 2.68 & $(3.38)$ & 4.18 & $(3.95)$ & $U=-2.020$ & $.043 *$ \\
\hline \multicolumn{7}{|l|}{ QLQ Variables } \\
\hline Physical Functioning & 0.79 & $(0.23)$ & 0.80 & $(0.18)$ & $U=-0.161$ & .872 \\
\hline Role Functioning & 0.71 & $(0.40)$ & 0.61 & $(0.43)$ & $U=-1.030$ & .303 \\
\hline Social Functioning & 1.35 & $(0.62)$ & 1.72 & $(0.82)$ & $U=-2.429$ & $.015^{*}$ \\
\hline Emotional Functioning & 1.60 & $(0.75)$ & 1.87 & $(0.55)$ & $U=-2.714$ & $.007 * *$ \\
\hline Cognitive Functioning & 1.48 & $(0.73)$ & 1.66 & $(0.75)$ & $U=-1.447$ & .148 \\
\hline Global Health Scale & 5.43 & $(1.37)$ & 5.14 & $(1.29)$ & $t(84)=0.985$ & .328 \\
\hline Fatigue & 1.63 & $(0.72)$ & 1.85 & $(0.67)$ & $U=-1.689$ & .091 \\
\hline Pain & 1.59 & $(0.91)$ & 1.46 & $(0.67)$ & $U=-0.309$ & .757 \\
\hline Nausea-vomiting & 1.15 & $(0.44)$ & 1.12 & $(0.30)$ & $U=-0.332$ & .740 \\
\hline Dyspnea & 1.24 & $(0.43)$ & 1.38 & $(0.57)$ & $U=-1.079$ & .281 \\
\hline Insomnia & 1.52 & $(0.74)$ & 1.76 & $(0.87)$ & $U=-1.297$ & .195 \\
\hline Loss of appetite & 1.19 & $(0.63)$ & 1.30 & $(0.55)$ & $U=-1.805$ & .071 \\
\hline Constipation & 1.24 & $(0.61)$ & 1.87 & $(0.95)$ & $U=-3.690$ & $.000 * *$ \\
\hline Diarrhea & 1.40 & $(0.76)$ & 1.29 & $(0.58)$ & $U=-0.671$ & .502 \\
\hline Financial impact & 1.43 & $(0.95)$ & 1.84 & $(1.07)$ & $U=-2.403$ & $.016^{*}$ \\
\hline
\end{tabular}

Note. Higher scores indicate higher identification with the variable and/or poorer functioning, except for the variables Physical Functioning and Role Functioning, in which higher scores indicate better functioning.

$* p \leq .05 . * * p<.01$. 
Firstly, after they had undergone surgery and had remained in the Transplantation Unit of the hospital, the patients' were divided into two subgroups (high and low post-transplantation anxiety) as a function of their Total Anxiety scores on the HAD (Zigmond \& Snaith, 1983). Specifically, the low post-transplantation anxiety group comprised 61 transplant patients with scores equal to or lower than $46.6 \%$, that is, a total score of 5 points or less. The 70 patients with scores higher than $46.6 \%$, that is, scores over 5 points, made up the high post-transplantation anxiety subgroup.

Secondly, to compare the differences one year after discharge in patients' and relatives' anxious and depressive symptomatology and quality of life in both patient subgroups (high and low post-transplantation anxiety), the following analyses were conducted: (a) first, we applied the normality test (Kolmogorov Smirnov test) to the 17 variables of interest assessed by the HAD and the QLQ in the patients (total anxiety score, total depression score, physical functioning, role functioning, social functioning, emotional functioning, and cognitive functioning, global health, fatigue, pain, and nausea-vomiting, dyspnea, insomnia, loss of appetite, constipation, diarrhea, and financial impact) and in the 6 variables assessed with the Leeds Anxiety and Depression Scales in the relatives (total anxiety-depression score, specific anxiety, specific depression, differential score, general anxiety and general depression); and (b) then, we applied Student's $t$ test to the variables with a normal distribution and the Mann-Whitney $U$ test to the variables that did not have a normal distribution.

\section{Results}

In the transplant patients, the following variables were statistically significant: total anxiety score, total depression score, social and emotional functioning, constipation, and financial impact, in which the patients who had higher previous levels of post-transplantation anxiety scored significantly higher (see Table 1). We then analyzed the items of all these variables (except for constipation and financial impact, which were individual items) to detect those that were more relevant in accounting for the differences. The items that reached the highest significance were related to the emotional sphere. More specifically, transplant patients with higher levels of post-transplantation

Table 2

Analysis of Items from the HAD (Anxiety, Depression) and the QLQ (Quality of Life) in Transplant Patients as a Function of their Post-Transplantation Anxiety One Year Ago

\begin{tabular}{|c|c|c|c|c|c|}
\hline \multirow[b]{3}{*}{ Items Assessed One Year Later } & \multicolumn{3}{|c|}{ Post-Transplant Anxiety } & \multirow[b]{3}{*}{ Value of Mann-Whitney $U$ Statistic } & \multirow[b]{3}{*}{$p$} \\
\hline & \multicolumn{2}{|c|}{ Low } & High & & \\
\hline & $M$ & $(S D)$ & $M(S D)$ & & \\
\hline \multicolumn{6}{|l|}{ HAD Items } \\
\hline \multicolumn{6}{|l|}{ Total Anxiety Score: } \\
\hline I feel tense or wound up & 0.75 & $(0.83)$ & $1.06(0.60)$ & -2.719 & $.007 * *$ \\
\hline $\begin{array}{l}\text { I get a sort of frightened feeling as if } \\
\text { something awful is about to happen }\end{array}$ & 0.57 & $(0.84)$ & $1.02(0.73)$ & -3.166 & $.002 * *$ \\
\hline Worrying thoughts go through my mind & 0.68 & $(0.98)$ & $1.17(1.00)$ & -2.466 & $.014^{*}$ \\
\hline I feel restless as if I have to be on the move & 0.69 & $(0.95)$ & $0.98(0.81)$ & -2.099 & $.036^{*}$ \\
\hline I get sudden feelings of panic & 0.29 & $(0.75)$ & $0.76(0.67)$ & -3.855 & $.000 * *$ \\
\hline \multicolumn{6}{|l|}{ Total Depression Score: } \\
\hline I feel cheerful & 0.34 & $(0.64)$ & $0.72(0.90)$ & -2.280 & $.023 *$ \\
\hline I look forward with enjoyment to things & 0.24 & $(0.53)$ & $0.53(0.75)$ & -2.060 & $.039 *$ \\
\hline \multicolumn{6}{|l|}{ QLQ Items } \\
\hline \multicolumn{6}{|l|}{ Social functioning: } \\
\hline \multicolumn{5}{|l|}{ Has your physical state or medical treatment } & $.016^{*}$ \\
\hline $\begin{array}{l}\text { Has your physical state or medical treatment } \\
\text { affected your social activities? }\end{array}$ & 1.37 & $(0.79)$ & $1.73(0.89)$ & -2.465 & $.014^{*}$ \\
\hline \multicolumn{6}{|l|}{ Emotional Functioning: } \\
\hline Have you felt nervous? & 1.77 & $(0.92)$ & $2.09(0.78)$ & -2.198 & $.028^{*}$ \\
\hline Have you felt depressed? & 1.31 & $(0.64)$ & $1.75(0.83)$ & -2.920 & $.004 * *$ \\
\hline
\end{tabular}

Note. Higher scores indicate higher degree of agreement with the item (except for items from the Total Depression Score-marked with $\checkmark$-where lower scores indicate more agreement with the item) and/or poorer functioning.

$* p \leq .05 . * *<.01$. 
Table 3

Relatives' Differences in Anxiety and Depression as Measured with the Leeds Anxiety and Depression Scales as a Function of Transplant Patients' Post-Transplantation Anxiety One Year Ago

\begin{tabular}{|c|c|c|c|c|c|c|}
\hline \multirow{3}{*}{$\begin{array}{l}\text { Variables from the Leeds Anxiety and Depression } \\
\text { Scale one Year after Transplantation }\end{array}$} & \multicolumn{4}{|c|}{ Post-Transplant Anxiety } & \multirow[b]{3}{*}{ Value of Contrast Statistic } & \multirow[b]{3}{*}{$p$} \\
\hline & \multicolumn{2}{|c|}{ Low } & \multicolumn{2}{|c|}{ High } & & \\
\hline & $M$ & $(S D)$ & $M$ & $(S D)$ & & \\
\hline Total Anxiety-Depression Score & 15.76 & $(10.68)$ & 23.44 & $(13.48)$ & $U=-2.789$ & $.007 * *$ \\
\hline Specific Anxiety & 3.51 & $(3.64)$ & 6.39 & $(4.46)$ & $U=-3.021$ & $.003 * *$ \\
\hline Specific Depression & 5.07 & $(3.81)$ & 5.78 & $(4.00)$ & $t(75)=-0.790$ & .432 \\
\hline Differential Score & 1.56 & $(4.24)$ & -0.61 & $(3.76)$ & $t(75)=2.359$ & $.021 *$ \\
\hline General Anxiety & 3.44 & $(3.50)$ & 6.36 & $(4.56)$ & $U=-3.166$ & $.002 * *$ \\
\hline General Depression & 4.59 & $(3.64)$ & 5.44 & $(3.72)$ & $t(75)=-1.021$ & .310 \\
\hline
\end{tabular}

Note. The higher the score, the higher the identification with the variable.

$* p \leq .05 . * * p<.01$.

Table 4

Analysis of Items of the Leeds Anxiety and Depression Scales Measured in Relatives One Year After Surgery of Transplant Patients

\begin{tabular}{|c|c|c|c|c|c|c|}
\hline \multirow[b]{3}{*}{ Items from Leeds Anxiety and Depression Scales } & \multicolumn{4}{|c|}{ Post-Transplant Anxiety } & \multirow[b]{3}{*}{ Value of Mann-Whitney $U$ Statistic } & \multirow[b]{3}{*}{$p$} \\
\hline & \multicolumn{2}{|c|}{ Low } & \multicolumn{2}{|c|}{ High } & & \\
\hline & $M$ & $(S D)$ & $M$ & $(S D)$ & & \\
\hline \multicolumn{7}{|l|}{ I get frightened or panic feelings for apparently } \\
\hline no reason at all & 0.39 & $(0.70)$ & 0.86 & $(0.99)$ & -2.314 & $.021 *$ \\
\hline I still enjoy the things I used to & 0.39 & $(0.66)$ & 0.75 & $(0.80)$ & -2.226 & $.026 *$ \\
\hline I am restless and can't keep still & 0.66 & $(0.72)$ & 1.19 & $(0.95)$ & -2.258 & $.011 *$ \\
\hline I am more irritable than usual & 0.95 & $(0.99)$ & 1.50 & $(1.02)$ & -2.311 & $.021 *$ \\
\hline I feel in some way to blame for the way I am & 0.66 & $(0.88)$ & 1.22 & $(1.14)$ & -2.212 & $.027 *$ \\
\hline I get bad headaches & 0.68 & $(0.75)$ & 1.19 & $(0.98)$ & -2.327 & $.020 *$ \\
\hline \multicolumn{7}{|l|}{ I get palpitations or a sensation of "butterflies" } \\
\hline in my stomach or chest & 0.73 & $(0.89)$ & 1.28 & $(1.11)$ & -2.225 & $.026 *$ \\
\hline I often think that I have done wrong & 0.66 & $(0.96)$ & 1.22 & $(1.09)$ & -2.441 & $.015^{*}$ \\
\hline I feel scared or frightened & 0.32 & $(0.68)$ & 0.78 & $(0.92)$ & -2.594 & $.009 * *$ \\
\hline I feel tense or wound up & 0.78 & $(0.88)$ & 1.58 & $(1.02)$ & -3.379 & $.001 * *$ \\
\hline
\end{tabular}

Note. Higher scores indicate higher degree of agreement with the item (except for the item marked with $\bullet$, where a lower score indicates more agreement) and poorer adjustment.

$* p \leq .05 . * * p<.01$

anxiety experienced stronger feelings and sensations of panic, fear, depression and tension one year later (see Table 2).

In the patients' relatives, the following variables reached significance: total anxiety-depression score, specific anxiety, differential score, and general anxiety. In all of them (except for the differential score), the relatives of the high-posttransplantation anxiety patients scored significantly higher than the low-anxiety group (see Table 3 ). We analyzed all the items of the Leeds Anxiety and Depression Scales to detect the items with more relevance in these differences. As in the group of patients, here also, the items with the highest significance were related to the emotional sphere. Specifically, the relatives of the high post-transplantation anxiety patients experienced more anxiety and feelings of fear one year later (see Table 4).

\section{Discussion}

In this investigation, we analyzed psychological differences in patients and their relatives as a function of the post-transplantation anxiety experienced one year ago by the patients themselves. 
Psychological differences (anxiety, depression, and quality of life) in patients as a function of their post-transplantation anxiety one year ago. Once the patients had undergone surgery and were discharged from the ICU, they had to remain hospitalized for some time in the Transplantation Unit of the hospital. The patients who, while in that unit, displayed higher levels of anxiety also displayed more anxious and depressive symptoms and had poorer quality of life at one-year follow-up. Mainly, four areas are affected: (a) psychological area: on the one hand, the patients displayed more anxious symptomatology ("I feel tense or wound up," "I get a sort of frightened feeling as if something awful is about to happen," "worrying thoughts go through my mind," "I feel restless as if I have to be on the move," and "I get sudden feelings of panic.") And on the other hand, they have more depressive symptomatology ("I feel depressed," "I do not feel cheerful," "I do not look forward with enjoyment to things"); (b) social area: their physical state or the treatment "affect their family life and their social activities negatively"; (c) physical area: they usually suffer from more digestive pathologies (for example, constipation); and (d) financial area: they usually have more "financial problems."

A possible explanation for these results may be that people who have recently undergone organ transplantation and who have a high level of anxiety are hypersensitive, that is, they are more concerned about minor bodily signs that would normally go unnoticed. In short, this emotional state can generate thoughts of excessive concern, for example, about the possibility of suffering organ rejection or an infection, which do not favor their long-term psychological and physical status. On the other hand, the anxious symptomatology may increase their lack of adherence to therapy, that is, their own psychological status will lead them to ignore health habits, which, in turn, would justify their having poorer quality of life one year after undergoing transplantation surgery (Dew et al., 2001; Dew, Switzer, et al., 2000; Owen et al., 2006).

In short, for some transplant patients, the threat of the loss of the transplanted organ, the constant or periodical symptoms associated with the secondary effects of immunosupressors, and the reminder of the diet or the medication are risk factors for their adaptation, both personal as well as social and family, although the affected individual may conceal this from others, especially from healthcare personnel (Magaz, 2006). Because of this, professionals must make an effort to detect patients with higher levels of post-transplantation anxiety, because negative emotional states could be the sole factor that most affects their quality of life after satisfactory organ transplantation (De Vito, Dew, \& Stilley, 2003). Therefore, it is appropriate to perform psychotherapeutic interventions to prevent illness, enhance reincorporation to work (which would also eliminate some financial problems), improve social support and, especially, increase adherence to medical treatment in order to preserve the function of the grafted organ (Valdés \& Ortega, 2006).
In accordance with this, the group of female transplant patients deserves special attention, especially if they must combine care of the implant with their desire to have children (Casanovas \& Cabré, 2007).

Psychological differences (anxiety, depression) in the relatives as a function of patients' previous posttransplantation anxiety. The transplant process also affects the family. Thus, for example, if after transplant, patients do not feel well psychologically, that is, they have a high level of anxiety, then they will probably transmit this psychological distress to their relatives, so that the latter will also display more anxious symptomatology: "they get frightened or panic feelings no apparently no reason at all," "they no longer enjoy the things they used to," "they feel restless and can't keep still," "they are more irritable than usual," "they feel in some way to blame for the way they are," "they get bad headaches," "they get palpitations, or a sensation of 'butterflies' in the stomach or chest," "they often think they have done wrong," "they feel scared or frightened," and "they are tense or wound up."

A possible explanation for these differences is that the relatives think that, due to the patients' psychological status, their physical evolution may be poor, to the point of rejecting the organ, and this has a negative effect on the relatives' own mood (Pérez, Martín, \& Pérez, 2005). On the other hand, it should be taken into account that the family requires support to cope with a series of stressors that usually appear after transplantation, for example, fear of the patient's death, the feeling that nobody is interested in the patient or his/her health, financial problems, and fear about whether the organ will work. If the family does not receive such support from their transplanted relative because the latter's level of anxiety prevents him/her from providing emotional, instrumental, and informational aid, then the family also suffers an increase of psychological disorders (Collins et al., 2000).

This mood of the family harms their transplanted relative, mainly because it prevents them from offering support. As a consequence, this increases the patients' psychological disorders and leads them to ignore medical prescriptions (Frazier et al., 2000; Pérez et al., 2000). In fact, in an investigation carried out with liver-transplant patients, it was verified that the patients who were in contact with depressive relatives presented more anxious symptomatology (Pérez et al., 2004).

Given that the psychological differences, not only in the patients but also in their closest relatives, could derive from post-transplantation anxiety, a series of psychotherapeutic strategies should be carried out in transplanted patients so that both they and their relatives could have the best quality of life possible, both at short and at long term.

We would like to point out the main limitation of this study that should be taken into account in future research. Specifically, a more exhaustive control of some sociodemographic and clinical variables should be undertaken in order to obtain groups as homogeneous as possible. 


\section{References}

Achille, M.A., Oullette, A., Fournier, S., Hebert, M.J., Girardin, C., \& Paquet, M. (2004). Impact of transplant-related stressors and feelings of indebtedness on psychosocial adjustment following kidney transplantation. Journal of Clinical Psychology in Medical Settings, 11, 63-73.

Arrarás, J.I., Illarramendi, J.J., \& Valerdi, J.J. (1995). El cuestionario de calidad de vida de la EORTC. Estudio estadístico de validación con una muestra española. Revista de Psicología de la Salud, 7, 13-33.

Beck, A.T., Rush, A., Shaw, B., \& Emery, G. (1979). Cognitive therapy of depression. New York: Guilford Press.

Bueno, A.M., \& Buceta, J.M.(1997). Tratamiento psicológico después del infarto de miocardio: estudios de caso. Madrid: Dykinson.

Caro, I., \& Ibáñez, E. (1992). La Escala Hospitalaria de Ansiedad y Depresión. Su utilidad práctica en psicología de la salud. Boletín de Psicología, 36, 43-69.

Casanovas, T., \& Cabré, L. (2007). Calidad de vida y recuperación después del trasplante hepático en el entorno femenino. Aspectos médicos, laborales, familiares y personales. In J. Pérez-Bernal (Ed.), Actualizaciones en trasplantes 2007 (pp. 105-108). Sevilla, Spain: Hospitales Universitarios Virgen del Rocío.

Christensen, A.J., Raichle, K., Ehlers, S.L., \& Bertolatus, J.A. (2002). Effect of family environment and donor source on patient quality of life following renal transplantation. Health Psychology, 21, 468-476.

Collins, E.G., White, C., \& Jalowiec, A. (2000). Spouse quality of life before and 1 year after heart transplantation. Critical Care Nursing Clinics of North America, 12, 103-110.

De Boer, J.B., Van Dam, F., \& Sprangers, M. (1995). Health-related quality of life evaluations in HIV-infected patients: A review of the literature. PharmacoEconomics, 8, 291-304.

De Vito, A., Dew, M.A., \& Stilley, C.S. (2003). Psychosocial vulnerability, physical symptoms and physical impairment after lung and heart-lung transplantation. Journal of Heart and Lung Transplantation, 22, 1268-1275.

Dew, M.A., DiMartini, A.F., Switzer, G.E., Kormos, R.L., Schulberg, H.C., Roth, L.H., \& Griffith, B.P. (2000). Patterns and predictors of risk for depressive and anxiety-related disorders during the first three years after heart transplantation. Psychosomatics, 41, 191-192.

Dew, M.A., Kormos, R.L., DiMartini, A.F., Switzer, G.E., Schulberg, H.C., Roth, L.H., \& Griffith, B.P. (2001). Prevalence and risk of depression and anxiety-related disorders during the first three years after heart transplantation. Psychosomatics, 42, 300-313.

Dew, M.A., Myaskovsky, L., DiMartini, A.F., Switzer, G.E., Schulberg, H.C., \& Kormos, R.L. (2004). Onset, timing and risk for depression and anxiety in family caregivers to heart transplant recipients. Psychological Medicine, 34, 1065-1082.

Dew, M.A., Myaskovsky, L., Switzer, G.E., DiMartini, A.F., \& Kormos, R.L. (2005). Profiles and predictors of the course of psychological distress across four years after heart transplantation. Psychological Medicine, 35, 1215-1227.

Dew, M.A., Switzer, G.E., DiMartini, A.F., Matukaitis, J., Fitzgerald, M.G., \& Kormos, R.L. (2000). Psychological assessment and outcomes in organ transplantation. Progress in Transplantation, 10, 239-261.

Frazier, P.A., Tix, A.P., Klein, C.D., \& Arikian, N.J. (2000). Testing theoretical models of the relations between social support, coping, and adjustment to stressful life events. Journal of Social and Clinical Psychology, 19, 314-335.

Garces, E., Velandrino, A., Conesa, P., \& Ortega, J. (2002). Un programa de intervención psicológica en pacientes con problemas cardiovasculares tipo inestable. Cuadernos de Psicología del Deporte, 2, 67-89.

Gledhill, J., Burroughs, A., Rolles, K., Davidson, B., Blizard, B., \& Lloyd, G. (1999). Psychiatric and social outcome following liver transplantation for alcoholic liver disease: A controlled study. Journal of Psychosomatics Research, 46, 359-368.

Hamilton, M. (1959). The assessment of anxiety status by rating. British Journal of Medical Psychology, 32, 50-55.

Hamilton, M. (1967). Development of a rating scale for primary depressive illness. British Journal of Social and Clinical Psychology, 6, 278-296.

Holzner, B., Kemmler, G., Kopp, M., Dachs, E., Kaserbacher, R., Spechtenhauser, B., Vogel, W., \& Sperner, B. (2001). Preoperative expectations and postoperative quality of life in liver transplant survivors. Archives of Physical Medicine and Rehabilitation, 82, 73-79.

Kellner, R., \& Sheffield, B.F. (1973). A self-rating scale for distress. Psychological Medicine, 3, 88-101.

Magaz, A. (2006). El distress psicológico asociado al trasplante y calidad de vida relacionada con la salud. In F. Ortega, \& P. Rebollo (Eds.), Calidad de vida relacionada con la salud de pacientes receptores de un trasplante de órgano sólido (pp. 37-42). Madrid: Ediciones Mayo.

Montero, I., \& León, O.G. (2005). Sistema de clasificación del método en los informes de investigación en psicología. International Journal of Clinical and Health Psychology, 5, 115-127.

Moreno, B., \& Kern, E. (2005). Calidad de vida relacionada con la salud infantil y el trasplante de órganos: una revisión de literatura. Revista Colombiana de Psicología, 14, 46-52.

Myaskovsky, L., Dew, M.A., Switzer, G.E., McNulty, M.L., Dimartini, A.F., \& McCurry, K.R (2005). Quality of life and coping strategies among lung transplant candidates and their family caregivers. Social Science and Medicine, 60, 2321-2332.

Ortega, F., \& Rebollo, P. (2004). La calidad de vida relacionada con la salud en pacientes portadores de un trasplante de órgano sólido. In J. Pérez-Bernal (Ed.), Actualizaciones en trasplantes 2004 (pp. 80-89). Sevilla, Spain: Hospitales Universitarios Virgen del Rocío.

Osoba, D., Zee, B., Pater, J., Warr, D., \& Latreille, J. (1994). Psychometric properties and responsiveness of the EORTC quality of life questionnaire (QLQ C-30) in patients with breast, ovarian and lung cancer. Quality of Life Research, 3, 353-364. 
Owen, J.E., Bonds, C.L., \& Wellisch, D.K. (2006). Psychiatric evaluations of heart transplant candidates: Predicting posttransplant hospitalizations, rejection episodes, and survival. Psychosomatics, 47, 213-222.

Pérez, M.A., Martín, A., Asián, E., \& Pérez, J. (2004). Symptoms of anxiety and depression in liver-transplant patients. Actas Españolas de Psiquiatría, 32 (4), 222-226.

Pérez, M.A., Martín, A., \& Galán, A. (2005). Problemas psicológicos asociados al trasplante de órganos. International Journal of Clinical and Health Psychology, 5, 99-114.

Pérez, M.A., Martín, A., Gallego, A., \& Santamaría, J.L. (2000). Influencia de algunas variables médicas y psicosociales en la recuperación psicológica de los trasplantados. Futuras líneas de intervención psicológica. Revista de Psicopatología y Psicología Clínica, 5, 71-87.

Pérez, M.A., Martín, A., \& Pérez, J. (2005). Salud mental de los familiares de los trasplantados. Psicothema, 17, 651-656.

Rodríguez, J., Pastor, M.A., \& López, S. (1993). Afrontamiento, apoyo social, calidad de vida y enfermedad. Psicothema, 5, 349-372.

Snaith, R.P., Ahmed, S.N., Mehta, S., \& Hamilton, M. (1971). The assessment of the severity of primary depressive illness. Psychological Medicine, 1, 143-149.

Snaith, R.P., Bridge, G.W., \& Hamilton, M. (1976). The Leeds Scales for the Self-Assessment of Anxiety and Depression. British Journal of Psychiatry, 128, 156-165.

Spielberger, C.D., Gorsuch, R.L., \& Lushene, R.E. (1970). Manual for the State/Trait Anxiety Inventory. Palo Alto, CA: Consulting Psychologists Press (Spanish version: TEA, 1982).

Tejero, A., Guimera, E., Farré, J.M., \& Perri, J.M. (1986). Uso clínico del HAD (Hospital Anxiety and Depression Scale) en población psiquiátrica: un estudio de sensibilidad, fiabilidad y validez. Revista del Departamento de Psiquiatría de la Facultad de Medicina de Barcelona, 12, 233-238.

The European Organization for Research and Treatment of Cancer QLQ-C30 (1993). A quality of life instrument for use in international clinical trials in oncology. Journal of the National Cancer Institute, 85, 365-376.

Trumper, A., \& Appleby, L. (2001). Psychiatric morbidity in patients undergoing heart, heart and lung, or lung transplantation. Journal of Psychosomatics Research, 50, 103-105.

Valdés, C., \& Ortega, F. (2006). Nuevas perspectivas en la evaluación de la calidad de vida relacionada con la salud en el trasplante de órgano sólido. In F. Ortega, \& P. Rebollo (Eds.), Calidad de vida relacionada con la salud de pacientes receptores de un trasplante de órgano sólido (pp. 225-231). Madrid: Ediciones Mayo.

Wang, L.Y., Chang, P.C., Shih, F.J., Sun, C.C., \& Jeng, C. (2006). Self-care behaviour, hope, and social support in Taiwanese patients awaiting heart transplantation. Journal of Psychosomatic Research, 61, 485-491.

Watanabe, T., \& Higara, S. (1999). Psychiatric symptoms during the week after renal transplantation. Transplantation Proceedings, 31, 251-253.

Zigmond, A.S., \& Snaith, R.P. (1983). The Hospital Anxiety and Depression Scale. Acta Psychiatrica Scandinavica, 67, 361370.

Received February, 15, 2007

Revision received July, 25, 2007

Accepted December, 1, 2007 